\title{
The Harwell Dekatron Computer
}

\author{
Kevin Murrell \\ Computer Conservation Society and The National Museum of Computing, UK \\ Kevin.murrelletnmoc.org
}

\begin{abstract}
The Harwell Dekatron Computer is a very early digital computer designed and built by the British Atomic Energy Research Establishment in 1952. The computer used British Post Office relays for control and sequencing, and Dekatron counting tubes for storage. After several years' service, it was passed to a college where it was used to teach computer programming, before being lost to various storage centres. In 2008 the machine was re-discovered and the decision was made to restore the computer to working order. This paper describes the machine and the choices and decisions made during the restoration process.
\end{abstract}

Keywords: Harwell Dekatron Computer, restoration, WITCH, National Museum of Computing, Dekatrons.

\section{Introduction: Restoring the Harwell Dekatron Computer}

Design of the computer began in 1949 using techniques that were generally well understood, and used components that were available to the Harwell engineers at the time. There seem to have been remarkably few problems with the design when it came to commissioning the machine and running the first few tests, and the computer was completed and first made to work properly in April 1951 using just two of the store units. This was sufficient to prove the machine was functioning correctly, and to allow simple programs to be written to test the machine more fully. By 1952, the team had added the remaining Dekatron store units and handed the computer over to the theoretical physics division for proper use.

The very conservative design of the computer was quite deliberate as it led to a reliable workhorse that could be left unattended to plough through a long series of calculations. Harwell kept precise records of the work done by the computer, and in a paper published in 1953 it was reported that in its first year with the division, from May 1952 to February 1953, the machine ran on average $921 / 2$ hours each week or for $55 \%$ of the total available time. Typically any lost time was when the machine had finished its allotted tasks and was waiting for its operators to arrive the next morning!

By 1957, the mathematicians at Harwell were making little use of the Dekatron Computer, but did not wish to see the machine broken up, so an imaginative competition was devised to make further use of the computer and give it a new home in education.

On the $25^{\text {th }}$ February 1957, Wolverhampton and Staffordshire College of Technology announced to the world they had won the competition and would soon receive the computer from Harwell. The official commissioning day in 
Wolverhampton was Wednesday, $4^{\text {th }}$ December 1957 , and at this point the machine was re-christened 'WITCH' - the 'Wolverhampton Instrument for Teaching Computation from Harwell'.

The college quickly established both a full time degree and a Diploma in Technology, and ran regular courses, many in the evening, to introduce computing to local colleges and schools. Computing moves at a frenetic space, and this was especially so during the 1960s and 1970s. The college made full use of the computer until 1973 when it was formally switched off and given to a local museum.

The computer was displayed in the museum for some time, but was eventually dismantled and put into long-term storage. In 2008, the author, by then the secretary of the Computer Conservation Society and a founder trustee of The National Museum of Computing in the UK, discovered a few parts of the machine and set about tracking down the remains of the computer. Quite quickly we discovered the bulk of the computer, albeit broken down into many pieces.

By now, there was a feeling of genuine excitement that this machine could be restored to working order and presented again for the public to see and appreciate. The work on collecting information about the machine continued in earnest, and again fate intervened when at an unrelated BCS (British Computer Society) meeting, we were given the contact details for Ted Cooke-Yarborough who was living near Abingdon - not far from Harwell. Ted was able to contact Dick Barnes, and very soon a meeting was arranged to tell them of our re-discovery of the machine and our plans for its restoration. The project team travelled to Abingdon in March 2009 to meet the two engineers to show them the results of our investigations and discuss our hopes to restore the machine to full working order. Barnes had kept a scrapbook of newspaper cuttings that proved very useful in understanding the history of the machine.

In April 2009 the project team wrote a formal restoration project plan to define what we hoped to achieve, what we needed to complete the project, and to detail any risks along the way. This plan was presented to the Computer Conservation Society (CCS) in May 2009 and was accepted as a new CCS Working Party. The CCS also kindly offered funds towards the initial costs of the project.

Some of the considerations we discussed were:

- Might we simply re-assemble the machine back to its original condition?

- Is enough of the original system available to consider its restoration to working order?

- Do we have the necessary tools and documentation?

- Do we have the sufficient spare parts that might be needed?

- How do we decide what might be replaced?

- Is original software available or accessible?

- Do we have the funds and the space to do this?

In September 2009, the machine was moved to its new home - the Large Systems Gallery at the National Museum of Computing. Even before any restoration work commenced, it was already attracting the curiosity of visitors, many of whom had never seen a computer looking anything like this machine with its rows of Dekatrons, valves and trigger tubes, and mysterious grey canisters filled with relays. 
Our objective therefore was to restore the machine to a state where it could be reliably and safely operated for demonstration to the public and the many educational and corporate groups who visit the museum.

In common with all our restoration work, the philosophy is to change as little as possible, particularly external appearance. Although it may be tempting to re-spray a rusty old machine, as one might routinely do when restoring a classic car, we feel this alters the character of the machine - we want our historic exhibits to look their age! In general we confine our activities to cleaning and conservation to prevent further degradation. On the Harwell machine we used electrolysis to treat the areas worst affected by rust.

This computer has had a uniquely long working life, during which it was extensively modified and repaired. We decided early on that we would not attempt to return it to an 'original' condition, and indeed, as work progressed, it became clear that establishing the exact details of the original design would be rather difficult in some areas.

Particularly in the power supplies, it was necessary to replace failed elderly components that are no longer available, some of these being quite prominently visible. In those cases the original components have been left in place, with the much smaller modern replacement components hidden from view. This helps to ensure the machine retains its unique character.

Restoration work fell into three main categories: relays, mechanical, and electronics. The machine came with full circuit diagrams, and an excellent detailed technical description written by Dick Barnes at Harwell. There was also a reasonable quantity of spare components.

Once work had begun in earnest we quickly discovered that the machine deviated from the diagrams in a number of areas, and furthermore that modifications had been made for which documentation hasn't survived. This has made the work more challenging than it might otherwise have been, and efforts are still on-going to fully document the machine in its current state.

\section{Relays}

The machine was built using Post Office 3000 type relays, which were at the time a mature and well understood technology. They were designed to operate for decades in the harsh environment of a telephone exchange, and consequently were extremely well made. A number of relays were discovered with bent contacts, and one concern was they may have been deliberately set out of normal adjustment to compensate for some timing problem within the design of the machine. In the event we have discovered very few areas that depend critically on relative relay timings.

The long and tedious job of relay adjustment has been rewarded by relatively trouble free operation of the complex relay logic of the machine, which at the time of writing has been working for over two years. During this period the machine has been regularly demonstrated to museum visitors by means of a simple program that reads from two tape readers alternately using block search and transfer control instructions. We anticipate an on-going need for periodic cleaning and adjustment of the relay sets. 


\section{$3 \quad$ Mechanical}

The output equipment consists of a Creed 7B printer, a Creed 75 tele-printer and a Creed 7TR re-perforator. All of these were specially modified at Harwell to operate with this machine. The printer and re-perforator date from the early 1940s, and so predate the rest of the machine by quite a few years.

The standard Creed models used serial I/O - a more primitive version of the RS232 serial port which until recently could be found on every modern PC. By contrast this machine uses parallel 5-wire I/O. There are standard 5-bit character codes, but in common with many other early computers this machine used a custom character set. One reason for this was to simplify the logic required to assure correct operation thus the numbers 0-9 that form the instruction code are all represented by combinations of two holes, and the block marking codes used to delineate program or data sections by combinations of three holes. This meant relatively simple logic could detect when an unexpected code was encountered and halt operation.

Restoration of these machines involved nothing more than a good clean and some adjustments - they really were built to last! Again we are fortunate to have experts in this technology at the museum who were able to carry out the work.

\section{$4 \quad$ Electronics}

Sequence control is entirely relay based, but arithmetic is all electronic, built using valves, trigger tubes and Dekatrons. There are also two high voltage power supply units - the rectifier unit converts the AC mains into several high DC voltages, and the stabiliser unit generates about a dozen precise DC voltages for use in the various circuits.

The rectifier unit has been extensively modified during the operational life of the machine, and now sports a variety of rectification technologies dating from the 1950s (copper oxide) to the present day (silicon diodes). We had to replace some of the original copper oxide rectifiers with modern components, but others had already been replaced during the machine's time at Wolverhampton. The other major problem in this unit was a leaking oil-filled transformer, eventually solved by copious use of Araldite. All the transformers in the machine were tested to ensure the insulation was still in good condition.

Once the power supplies were operating reliably we turned our attention to the pulse generator, which is one of the most complex parts of the machine. Its main job is to generate various sequences of pulses to step the Dekatrons, but it also has a hand in starting arithmetic operations, deciding when they are complete, and controlling the transfer and carry units which perform the actual addition and subtraction operations. Some of the subtler (and undocumented) aspects of its operation only became clear when it was back on the racks and interacting with the rest of the machine.

The majority of the work was done with the pulse generator on the bench, with a few switches connected up to provide control inputs. We found around half a dozen failed components - mainly diodes and capacitors. The other major issue has proven to be the high-speed trigger tubes which start and stop the Dekatron used in the pulse 
generator to count out ten pulses. We had a large supply of spare tubes that came with the machine, but the majority turned out not to work. We were lucky to find a supplier who allowed us to test their entire stock of several hundred, but this only yielded a small number of working ones, and some of these no longer work at the time of writing. The most likely explanation is the gas has escaped around where the pins enter the base - this is surprising since the problem of making valves reliably gas tight had been largely solved by the early 1950s. Keeping the machine running long term will eventually require a modification of these circuits to use a more reliable type of trigger tube.

The remainder of the units in the arithmetic rack were repaired one at a time on the bench with the help of the pulse generator and power supplies. These consist of the two halves of the accumulator, which also contain plug-in transfer and carry modules, and the translator unit that converts between 5-wire code and Dekatron compatible pulse trains. The translator is used both when reading numbers from tape into store and when printing out from store. No major issues were found with any of these units bar a handful of failed components.

With the arithmetic rack completed we turned our attention to the stores. The only major problem that Dekatrons suffer from is contamination of adjacent electrodes due to the glow being left on one cathode for a long period of time. This results in 'sticky' operation - either the glow won't reliably step past a particular cathode, or jumps straight over it. Both of these problems cause an incorrect answer. Luckily the process can be reversed by simply allowing the Dekatron to 'spin' for a long enough period.

No detailed operational log of the machine survives, but it's likely some of these faults have been present for many years and were probably partly responsible for the unreliability which we know the machine developed in its later life. These circuits must only just have worked when the machine was new, and hence even small component value changes caused a problem.

The goal of the restoration was to have the machine fully working and as reliable as it was when new. At the time of writing this has largely been achieved, with only a few reliability issues left to solve. The machine is once again able to run the original programs written for it in the 1950s.

The museum plans to produce teachers and students information packs about the machine that can be downloaded in advance of their visit. The packs will include detailed instructions on how the machine is programmed, example programs and potential programming challenges. We also hope to include a software emulation of the computer so that students can prepare programs prior to their visit, and then on the day actually run them on the live machine.

Very little remains of the history of computing in the UK from the late 1940s and early 1950s, and we are very lucky that this machine has led such as charmed life and managed to 'avoid the chop' on several occasions. Its important early role in pioneering nuclear technology, its long second life in education, and its third life as a museum exhibit enthusing young people, can now continue as an active machine enthusing and helping train a new generation of engineers and programmers. 